\title{
THE CHEMICAL TREATMENT OF WASTEWATER DISCHARGED FROM SAUSAGE CASING INDUSTRY
}

\author{
Abdel Razek, T. M. ${ }^{(1)}$; El Gendy, A. Sh. ${ }^{(1)}$ and Abdel Hameed M. A. \\ 1) Institute of Environment Studies and Research, Ain Shams University
}

\begin{abstract}
This study focused on effluents wastewater treatment from sausage preparation using physical and chemical treatment by coagulation and flocculation processes. Choice of a suitable coagulant for maximum contaminant removal and reduction in costs is the most important factor. The feasibility of using aluminum sulfate, poly aluminum chloride (PAC) and ferric chloride in sausage wastewater treatment has been investigated. Removal of water pollutants discharged from industrial sausage wastewater is required to comply with the environmental standards. The study was conducted using poly aluminum chloride dosage $(40-140 \mathrm{mg} / \mathrm{l})$, ferric chloride dosage $(40-140 \mathrm{mg} / \mathrm{l})$ and alum dosage (100 - $600 \mathrm{mg} / \mathrm{l})$ individually. The efficiency of COD, BOD, TSS, Oil and Grease and TKN removal recorded (98\%), (97\%), (97\%), (95\%), $(97 \%)$ respectively using a dose $140 \mathrm{mg} / \mathrm{l}$ of PAC. While using a dose $140 \mathrm{mg} / \mathrm{l}$ of ferric chloride recorded (96\%), (93.5\%), (95.5\%), (89.4\%), (95.4\%), respectively and using a dose $600 \mathrm{mg} / \mathrm{l}$ of alum recorded (95.6\%),(94.3\%), (96.5\%), (92\%), (95\%), respectively.
\end{abstract}

Keywords: Flocculation, Coagulation, Chemical treatment, Sausage preparation wastewater.

\section{INTRODUCTION}

Meat has been and continues to be a central element of diets in developed countries. Processed meat products (sausages, burgers and meat pies) accounts for almost half of the meat being consumed in these countries. Projections suggest that the global consumption of meat will continue to increase moderately over the next 40 years. This increase reflects the 
increasing demand for meat and poultry (Kearney, 2010). With increasing market demand, meat processors are driven to invest in research and innovation to remain competitive (Chen et al., 2013). Meat processors must meet consumer preferences as one of the keys to developing a successful product (Chen et al., 2013). There have been rapidly changing consumer demands in the food industry improved health, safety, quality, convenience, value, experience as well as addressing ethical and environmental issues (Kearney, 2010). Sausage preparation industry is one of it and it's very important due to the increasing demand for fast food but it causes heavy pollution. Animal casings are the oldest form of casings used and are considered to have superior moisture vapor transmission and have a wide range of mechanical properties, depending on the type and preparation of the casing (Savic and Savic, 2002). The process of casings preparation as follows: pre- washing then washing then filling with water then cutting to same length and sectors then salting. Wastewater can be defined as the remaining spent water that has been used by humans in homes, commercial establishments, industries, public institutions, and similar entities for various purposes (Sincero and Sincero, 2003). Wastewater collected in municipal sewer systems is comprised of domestic or 'sanitary' wastewater, industrial wastewater, infiltration and inflow into sewer lines, and storm water runoff (Canter and Harfouche, 2000). In modern water treatment, coagulation and flocculation are still essential steps in the treatment processes. The initial step is simple: the chemical is added to wastewater. This is followed by the second step, where the solution is mixed rapidly in order to make certain that the 
chemicals are evenly and homogeneously distributed throughout the wastewater. In the third step, the solution is mixed again, but this time in a slow fashion, to encourage the formation of insoluble solid precipitates, the process known as "coagulation". The final step is the removal of the coagulated particles by way of filtration or decantation (Y1lmaz et al, 2007). Thus, conventional coagulation practices may provide excellent organic removal if the coagulant dose and $\mathrm{pH}$ conditions are adjusted into the optimum range. Organic removal increased with an increasing alum dose and alum doses higher than the normally used for turbidity removal, are needed to obtain the best organic removal. Poly aluminum chlorides, poly aluminum sulfates, or poly aluminum chloro-sulfates, with variable degrees of polymerization, especially the first one are used extensively worldwide during the last decades, with an ever increasing demand. Their properties were intensively examined and have proven to be more efficient in lower dosages, in wider $\mathrm{pH}$, temperature and colloids concentration ranges, than the conventional simpler ones, leading to cost and operative more effective treatment (Sinha et al., 2004; Crittenden et al., 2005). Polyaluminium chlorides are similar to alum except contain high charge polymeric aluminum species as well as the monomer. Al13 with the formula A113O4 $(\mathrm{OH}) 24(\mathrm{H} 2 \mathrm{O}) 127$ has been shown to dominate species (Parthasarathy and Buffle, 1985; Bertsch and Thomas, 1986; Bertsch, 1987). The iron salts most commonly used as coagulants include ferric sulfate, ferric chloride and ferrous sulfate. These compounds often produce good coagulation when conditions are too acidic for best results with alum. Sometimes the particles 
are best removed under acidic conditions, and also iron compounds give better results (Tripathy and De, 2006).

The aim of this research is treatment for industrial sausage wastewater to comply with the environmental laws.

\section{MATERIAL AND METHODS}

\section{Study area:}

The Company is located in Alexandria free zone, on $29^{\text {th }} \mathrm{Km}$ of Alexandria-Cairo desert highway, $6^{\text {th }} \mathrm{km}$ from El Dekhila harbor, $20^{\text {th }} \mathrm{km}$ from El Nozha airport, and $30^{\text {th }} \mathrm{km}$ from Alexandria airport which is situated in Alexandria, Egypt.

\section{Jar test:}

Stock solutions of ferric chloride, alum and poly aluminum chloride were prepared before starting the experiment. The solutions were prepared by dissolving $10 \mathrm{~g}$ of each substance in distilled water and the solution volumes were completed to 1 liter. Each $1 \mathrm{ml}$ of these stock solutions was equivalent to $10 \mathrm{mg} / \mathrm{l}$ when added to $1000 \mathrm{ml}$ of wastewater. They have been prepared in three different concentrations, a conventional jar test apparatus was used in the experiments to coagulate sample of the sausage wastewater by using ferric chloride and alum and poly aluminum chloride. It was carried out as a batch test, accommodating a series of six beakers together with six-spindle steel paddles .Wastewater samples were collected from Sausage Casing Company. Samples were collected, and stored in several polyethylene bottles. Wastewater were mixed homogeneously then, samples were analyzed to 
measure pH, T.S.S and COD for representing an initial concentration. After the desired amount of alum, poly Aluminum chloride and ferric chloride was added to the suspension, the beakers were agitated at various mixing time and speed, which consist of rapid mixing (150 rpm) for 1 minute and slow mixing $(30 \mathrm{rpm})$ for 10 minutes to coagulation. Then $4 \mathrm{ppm}$ anionic polymer was added. Then 5 ppm sod. Hypo chlorite was add after the agitation being stopped, the suspension was allowed to settle for 20 minutes. Finally, a sample was withdrawn using a pipette from the top inch of supernatant for $\mathrm{pH}$., total suspended solids and COD and measurements which representing the final concentration. All tests were performed at an ambient temperature in the range of $20-25^{\circ} \mathrm{C}$. The study was conducted by varying the experimental parameters, which were poly aluminum chloride dosage (40, 60, 80, 100, 120 and $140 \mathrm{mg} / \mathrm{l})$ Ferric chloride dosage (40, 60, 80, $100,120$ and $140 \mathrm{mg} / \mathrm{l})$ and alum dosage (100, 200,300,400,500 and 600 $\mathrm{mg} / \mathrm{l})$.

\section{RESULTS AND DISCUSSION}

Sausage preparation waste water analysis: Table 1 shows that wastewater discharged from sausage preparation is not in compliance with the environmental laws in many aspects. COD exceeded the limit set by law 93/ 1962 Decree 44/2000, BOD not comply, and so sausage preparation wastewater must be treated to comply with environmental laws. 
Table (1): Analysis of wastewater sample from sausage preparation industry

\begin{tabular}{|c|c|c|c|c|c|c|}
\hline NO. & ITEMS & $\begin{array}{l}\text { Sample } \\
\text { (1) }\end{array}$ & $\begin{array}{c}\text { Sample } \\
\text { (2) }\end{array}$ & $\begin{array}{c}\text { Sample } \\
\text { (3) }\end{array}$ & Average & $\begin{array}{c}\text { Decree } \\
44 / 2000\end{array}$ \\
\hline 1 & pH Value & 7.78 & 7.65 & 7.65 & $7.69 \pm \mathrm{SD}$ & $6.5-9.2$ \\
\hline 2 & TSS & 1732 & 1680 & 1900 & $1770 \pm$ SD & 800 \\
\hline 3 & VSS & 821 & 857 & 1202 & $960 \pm \mathrm{SD}$ & -- \\
\hline 4 & $\mathrm{BOD}_{5}$ & 1100 & 1320 & 1450 & $1290 \pm \mathrm{SD}$ & 800 \\
\hline 5 & $\begin{array}{l}\text { Soluble } \\
\text { BOD }_{5}\end{array}$ & 610 & 680 & 900 & $730 \pm \mathrm{SD}$ & -- \\
\hline 6 & COD cr & 1815 & 1850 & 2320 & $1995 \pm$ SD & 1100 \\
\hline 7 & $\mathrm{PO}_{4}$ & 41 & 45.32 & 48.32 & $44.9 \pm \mathrm{SD}$ & 25 \\
\hline 8 & $\mathrm{~N}-\mathrm{NO}_{3}$ & 29.7 & 35.65 & 35.00 & $33.5 \pm \mathrm{SD}$ & -- \\
\hline 9 & $\mathrm{~N}-\mathrm{NH}_{3}$ & 21.81 & 24.98 & 27.00 & $24.6 \pm \mathrm{SD}$ & -- \\
\hline 10 & Oil/Grease & 122 & 120 & 122 & $121 \pm \mathrm{SD}$ & 100 \\
\hline 11 & TKN & 53.7 & 45.54 & 38.90 & $46 \pm \mathrm{SD}$ & -- \\
\hline
\end{tabular}

\pm Standard deviations

TKN: Total Kjeldahl nitrogen

Treatment with alum:-

The efficiency of COD, BOD, TSS, O\&G and TKN removal using alum, was $(95.6 \%)$, while BOD removal was (94.3\%), TSS removal was $(96.5 \%)$, TKN removal was $(95.3 \%)$ and O\&G removal was $(92.14 \%)$. 


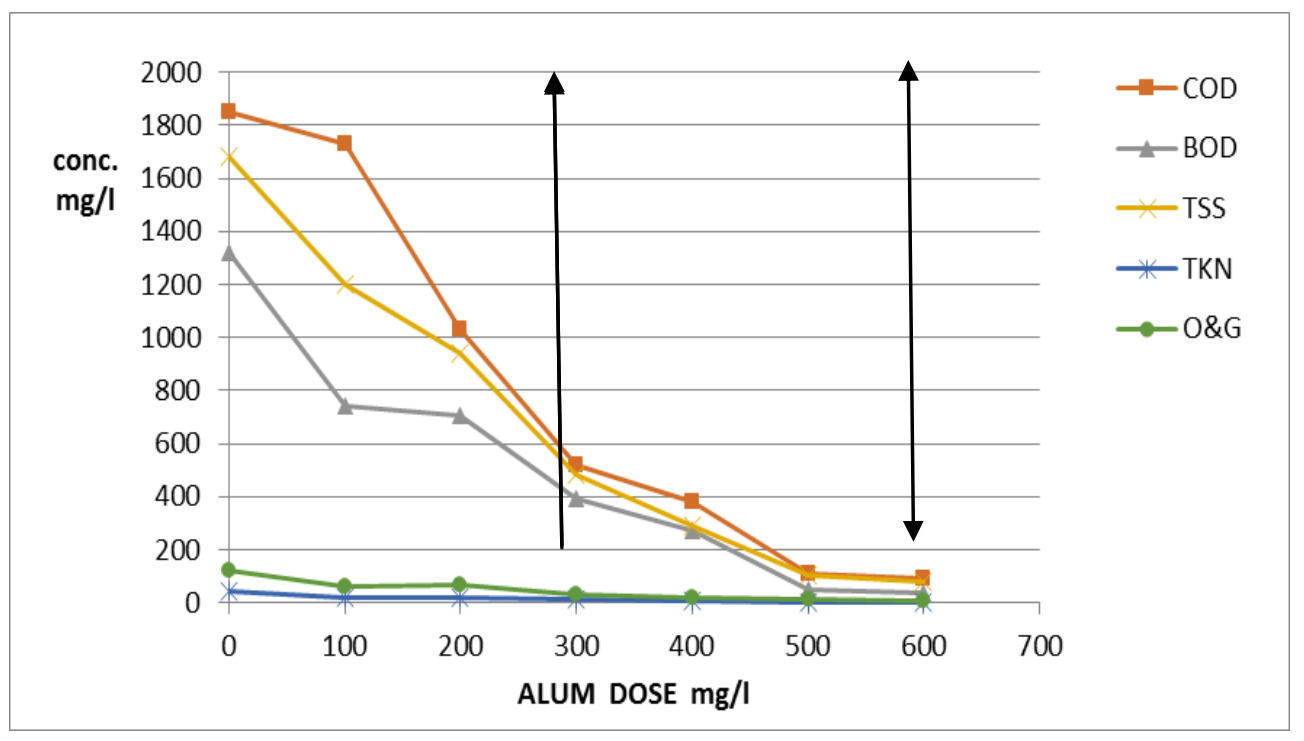

Fig (1): Water pollutants as a function of Alum dose ( $\mathrm{mg} / \mathrm{l})$

The obtained results were in agreement with Saatci et al., 2001 who reported that the efficiency of COD removal was $92.11 \%$ and the efficiency of oil \& grease removal was $92.99 \%$ for Vegetable oil industry. Also, results showed an agreement with the results reported by Ghaly et al., 2006 for greasy waste water where using aluminum sulfate as coagulant achieved an efficiency of total solid (90\%).

\section{Treatment with ferric chloride:-}

The efficiency of COD, BOD, TSS, O\&G and TKN removal using ferric chloride was as follows: was (96\%) while, BOD removal was (93.5\%), TSS removal was $(95.5 \%)$, TKN removal was $(95.43 \%)$ and $\mathrm{O} \& \mathrm{G}$ removal was $(89.43 \%)$. 
J. Environ. Sci.

Institute of Environmental Studies and Research - Ain Shams University

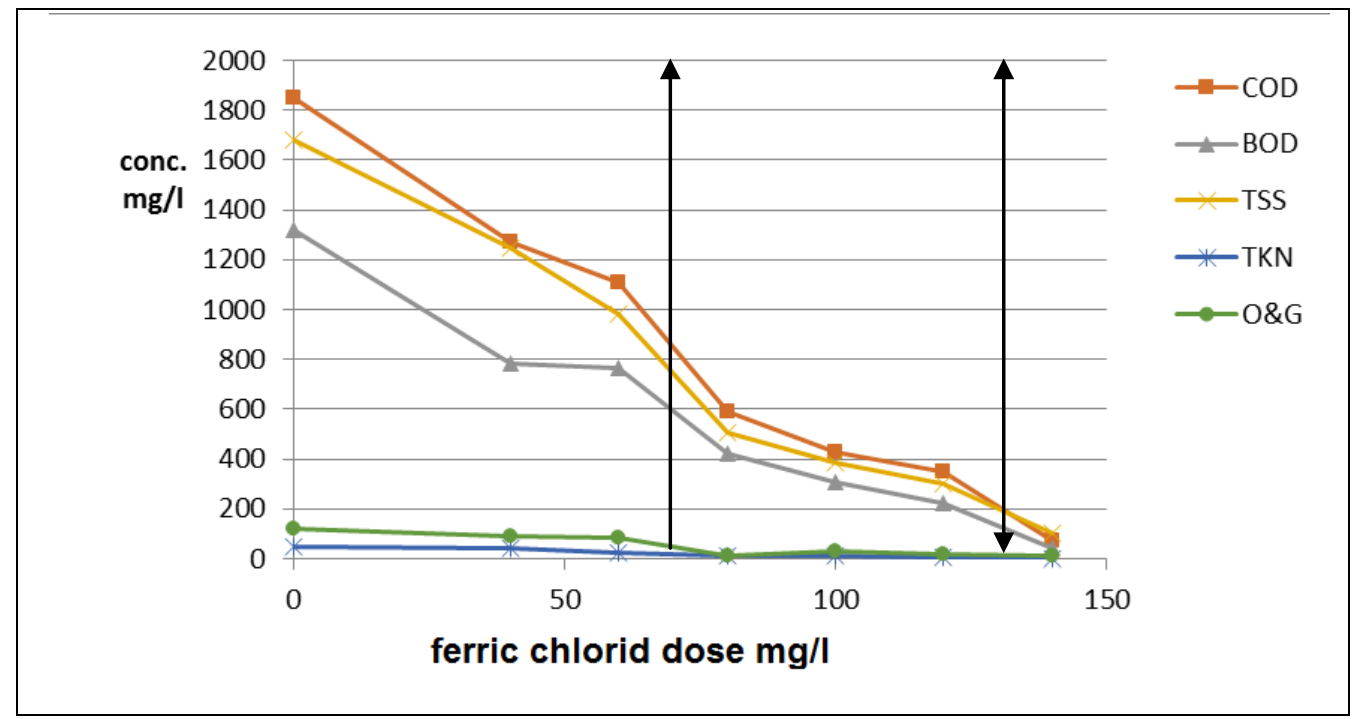

Fig (2): Water pollutants as a function of ferric dose $(\mathrm{mg} / \mathrm{l})$

The obtained results were in agreement with Saatci et al., 2001 who reported that the efficiency of COD removal was $96.25 \%$ and the efficiency of oil \& grease removal was $96.11 \%$ for Vegetable oil industry. Also, results showed an agreement with Moghaddam et al., 2010 who mentioned that using a dose $(140 \mathrm{mg} / \mathrm{l})$ of ferric Chloride as coagulant achieved an efficiency of removed dye was $96.3 \%$. Also, results showed an agreement with the result reported by Ghaly et al., 2006 for greasy waste water by using a dose $140 \mathrm{mg} / \mathrm{l}$ of ferric chloride as coagulant achieved efficiency of total solid (88 \%). Also, results showed an agreement with Lianga et al., 2009 for molasses waste water by using dose $(3.5 \mathrm{~g} / \mathrm{l})$ of ferric chloride as coagulant the efficiency of COD removal achieved (86\%). 


\section{Poly aluminum Chloride (PAC):}

The efficiency of COD , BOD , TSS , O\&G and TKN removal using poly aluminum chloride was as follows: COD (98\%) while, BOD removal was (97.6\%), TSS removal was (97.6\%), TKN removal was $(97.47 \%)$ and O \& G removal was $(95.17 \%)$.

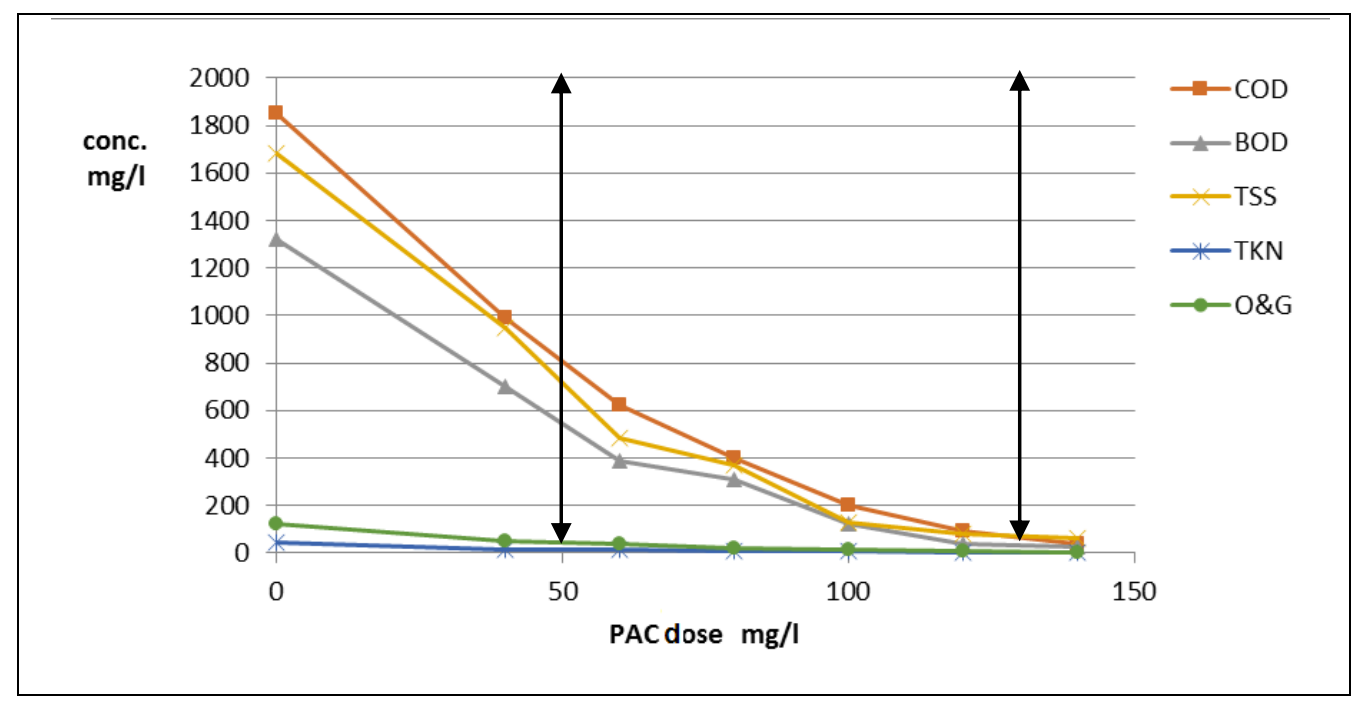

Fig (3): Concentration of water pollutants with PAC dose (mg/l)

The obtained results were in agreement with Sabur et al., 2012 who reported that the efficiency of COD removal was $(90.17 \%)$ and the efficiency of turbidity removal was achieved (93.47\%) for textile industry. Also, results showed an agreement with Kadhum et al., 2011 who mentioned that the efficiency of COD removal was $(91.12 \%)$ and the efficiency of turbidity removal was achieved (93.13\%) for pulp and paper industry. Also, results were in agreement with Kumar et al., 2011 who mentioned that efficiency of COD removal achieved ( $84 \%)$ for pulp and paper industry. 
J. Environ. Sci.

Institute of Environmental Studies and Research - Ain Shams University

\section{CONCLUSION}

The focus of this paper was to select the best coagulant and the good dose to investigate the potential use of coagulation process for the removal BOD, COD, O \& G, TKN and TSS from industrial effluents sausage casing wastewater using ferric chloride, alum and poly aluminum chloride was investigated. The experiments conducted confirm the significant effect of coagulant dosage on coagulation process. Under optimal conditions of process parameters, in this work alum, poly aluminum chloride (PAC) and ferric chloride were used to coagulate the suspended solid in the wastewater it was found that the behavior of coagulant may change from wastewater to another according to many factors including kind of coagulant and different constituents of wastewater. The efficiency of COD, BOD, TSS, $\mathrm{O} \& \mathrm{G}$ and TKN removal was achieved by using poly aluminum chloride by (98\%), (97\%), (97\%), (95\%), (97\%) respectively. It can be deduced that, increasing the coagulant dosage increasing the efficiency of coagulant in removal. Alum is one of the common and cheapest coagulants used to the treatment purpose.

\section{REFERENCES}

APHA, (1992): Standard Methods for the Examination of Water and Wastewater. $18^{\text {th }}$ ed.

Bertsch, P. M. (1987): Conditions for Al (13) Polymer Formation in Partially Neutralized Aluminum Solutions. Soil Science Society of America Journal 51, pp. 825-828. 
Bertsch, P. M and Thomas, G. W. (1986): Characterization of HydroxyAluminium solution by aluminum 27 Nuclear Magnetic Resonance Spectroscopy, Soil Science Society of America Journal 50, pp. 825:828.

Canter, L. W. and Harfouche, N. (2000): Sources and Characteristics. In: Wastewater Treatment. D. H. F, Liu and B. G, Liptak (Editors). Lewis Publishers, New York, New York. pp. 114-142.

Chen, Q.; Anders S. (2013): Measuring consumer resistance to a new food technology; a choice experiment in meat packaging. Food Quality and Preference 28:419-428.

Crittenden, J. C.; Trussel, R. R. and D.W. Howe, K.J., Tchobanoglous, G., and (Eds).,(2005): Coagulation, mixing and flocculation, in: Water Treatment: Principles and Design, second ed., John Wiley and Sons, New Jersey, 643-779.

Ghaly, A. E.; Snow, A. and Faber, B. E. (2006): Treatments of grease filter wash water by chemical coagulation. Canadian Bio systems Engineering/Le genie des Bio systems au Canada 48, 6.13-6.22.

Kadhum, M. Shabeeb, Hayder, A., Abdul Bari, Hayder, and Abdul Bari, (2011): Treatment Of Pulp And Paper Mill Wastewater By PolyAluminum- Silicate-Chloride (Pasic) Through CoagulationFlocculation Process, Al-Qadisiya Journal For Engineering Sciences 4(4), pp. 546-555.

Kearney, J. (2010): Review; Food consumption trends and drivers. Philosophical Transitions of the Royal Society B 365:2793-2807.

Kumar, P.; Teng, T. T.; Chand, S. and Kailas, L. (2011): Wastewater, Treatment of Paper and Pulp Mill Effluent by Coagulation, International Journal of Civil and Environmental Engineering 3, 3.

Lianga, Z.; Wang, Y.; Zhoub, Y. and Liu, H. (2009): Coagulation removal of melanoidins from biologically treated molasses wastewater using ferric chloride, Chemical Engineering Journal 152, pp. 88-94. 
Moghaddam, S. S.; Moghaddam; Alavi, A. R. and Arami, M. (2010): Decolonization of an Acidic Dye from Synthetic Wastewater by Sludge of Water Treatment Plant, Iran Journal of Environment Health Science Engineering 7(5), 437-442.

Parthasarathy, N. and Buffle, N. (1985): Study of polymeric Aluminum (III) Hydroxide of solution for Application in waste water treatment properties of the polymer and optimal condition of preparation, Water Research 19(1), pp. 25-36.

Saatci, Y.; Hasar. H. and Cici, M. (2001): Treatability of Vegetable Oil Industry Effluents through Physical-Chemical Methods, Fresenius Environmental Bulletin 10(12).

Sabur, M. M.; Khan, A. A. and Safiullah, S. (2012): Treatment of Textile Wastewater by Coagulation Precipitation Method, Journal of Scientific Research 4 (3), pp. 623-633.

Savic, Z. and Savic, I. (2002): Sausage Casings. 1st Edition. Austria: Victus. p. 354.

Sincero, A. P. and Sincero, G. A. (2003): Physical-Chemical Treatment of Waste and Wastewater. CRC Press, New York, New York.

Sinha, S.; Yoon, Y.; Amy, G. and Yoon, J. (2004): Determining the effectiveness of conventional and alternative coagulants through effective characterization schemes, Chemosphere 57, pp. 11151122.

Tripathy, T. and De, B. R. (2006): Flocculation: A New Way to Treat the Waste Water, Journal of Physical Sciences, 10, pp. 93-127.

Ylmaz, A. E.; Boncukcuoğlu, R. and Kocakerim, M. M. (2007): A Quantitative Comparison between Electrocoagulation and Chemical Coagulation for Boron Removal from BoronContaining Solution. Journal of Hazardous Materials 149, pp. 475-48. 


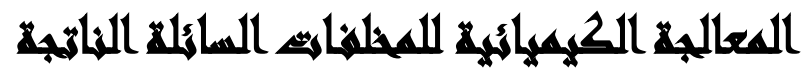 次}

[६]

طه عبد العظيم محمد عبد الرازق(')- أحمد شفيق الجندي(')- محمد عاصف عبد الحميد

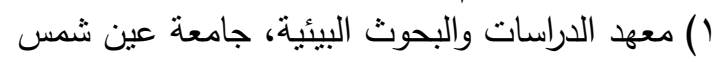

\section{المستخليف}

تعد صناعة تجهيز الأمعاء من الصناعات العريقة وكذلك تُعد من الصناعات المنتشرة عالمياً

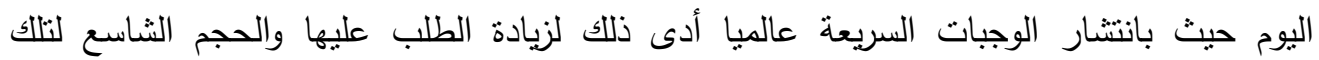

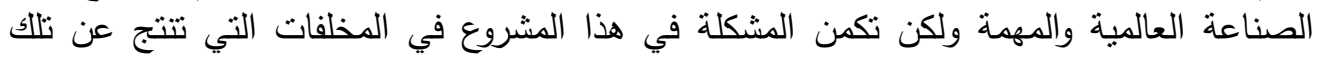

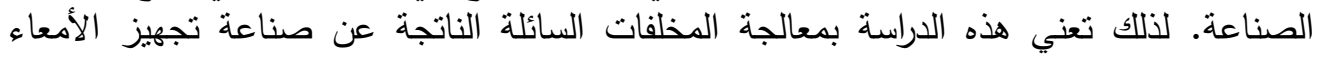

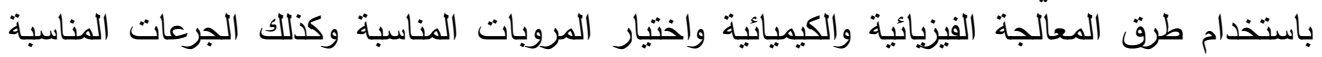

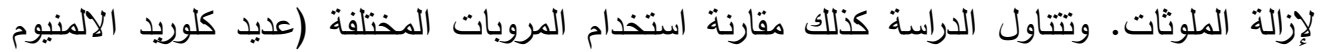

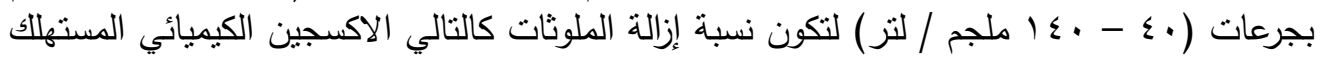

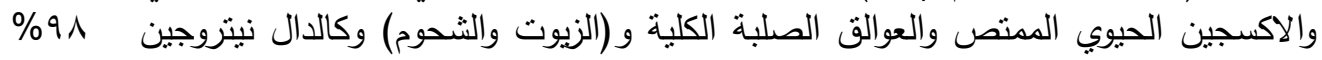

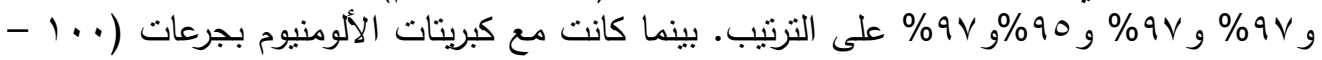

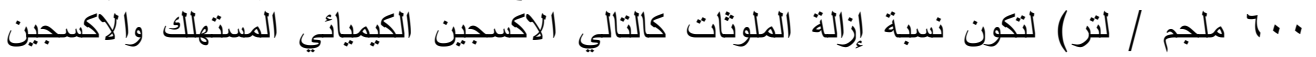

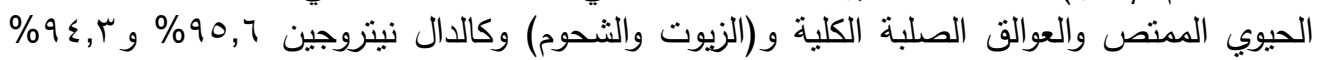

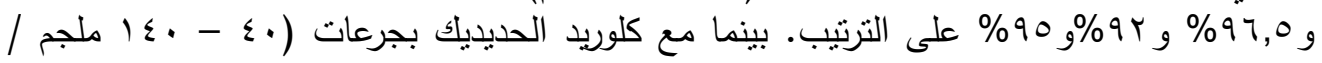

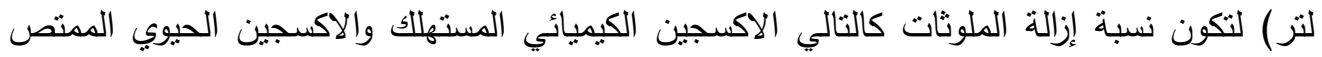

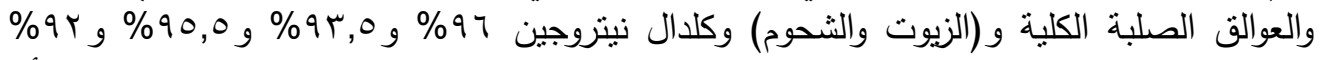

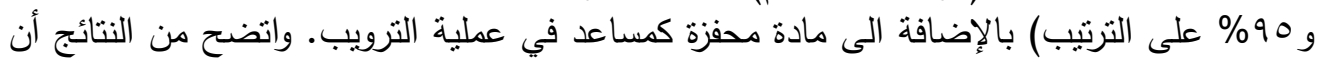

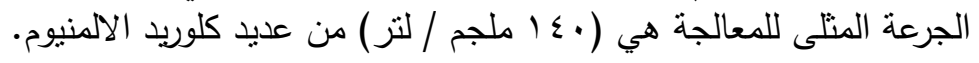

